\title{
Current Status and Correlates of Modern Family Planning Utilization in Hard to Reach Ethnic Minorities: The Case of Gumuz, Northwest Ethiopia
}

\author{
Molla Gedefaw ${ }^{1}$, Dawit Muluneh2, Mekonen Aychiluhem ${ }^{1}$ \\ ${ }^{1}$ GAMBY College of Medical Sciences, Bahir Dar, Ethiopia \\ 2Joint MPH Program, GAMBY College of Medical Sciences, Bahir Dar University, Bahir Dar, Ethiopia \\ Email: mollagedefaw@yahoo.com, dawitmuluneheresso@gmail.com, mekachy@yahoo.com
}

Received 8 August 2014; revised 8 September 2014; accepted 8 October 2014

Copyright (C) 2014 by authors and Scientific Research Publishing Inc.

This work is licensed under the Creative Commons Attribution International License (CC BY).

http://creativecommons.org/licenses/by/4.0/

(c) (i) Open Access

\section{Abstract}

Cognizant of multifaceted challenge of unwanted pregnancy, Ethiopia strives to increase utilization of modern family planning across the nation. Therefore, update on the current status of family planning utilization especially in hard to reach ethnic minorities is critical. The objective of this study was to assess level, and correlates of modern contraceptive utilization in a hard to reach ethnic minorities. A community based study was conducted in Dangur District, Beneshangul Gumuz Regional State July, 2013. A total of 530 married women were included in the study. Structured questionnaire was data collection tool. Data was analysed using SPSS version 20 for windows. Possible association and their strength were measured using odds ratio at $\mathbf{9 5 \%}$ CI. Family planning utilization was $18.7 \%$ while nearly $27 \%$ of study participants had ever used family planning methods. The following variables were predictors of family planning utilization: number of alive children [AOR: 3.31, 95\% CI (1.41 - 7.20)], good knowledge [AOR: 2.18, 95\% CI (1.35 - 3.52)] and positive attitude [AOR: 1.58, 95\% CI (1.03 - 2.50)]. The most outstanding finding of this study was that more than $80 \%$ of study participants still believe that many children means high income, and nearly $60 \%$ of them believe that family planning utilization decreases confidence among couples. This study witnessed how successful Ethiopia is in addressing reproductive health service inequalities in hard to reach communities. However, misconceptions surrounding family planning, and culture associated desire to have large family size should be addressed in a culture sensitive manner so that this success would further bear fruits.

\section{Keywords}

Family Planning, Benshangul-Gumuz, Hard to Reach, Ethnic Minorities, Ethiopia

\footnotetext{
${ }^{*}$ Corresponding author.
}

How to cite this paper: Gedefaw, M., Muluneh, D. and Aychiluhem, M. (2014) Current Status and Correlates of Modern Family Planning Utilization in Hard to Reach Ethnic Minorities: The Case of Gumuz, Northwest Ethiopia. Open Journal of Epidemiology, 4, 188-198. http://dx.doi.org/10.4236/ojepi.2014.44025 


\section{Introduction}

The twenty-third round of official United Nations population estimates and projections indicates that the 7.2 billion world population in mid-2013 is projected to reach 8.1 billion in 2025. This figure will increase to 10.9 billion by 2100 [1]. The major segment of the projected population growth will take place in low and middle income countries of Africa and Asia [2] [3]. Over half of the increase is expected to occur in only eight countries. Ethiopia is one of them [1].

Being the second most populous nations of Africa [4], Ethiopia is a prototype example of nations which has been facing multitudes of challenges following rapid population growth including environmental degradation, chronic food insecurity, high maternal, and child mortality [5]. It is surprising to notice that the population of Ethiopia has doubled itself between 1980 and 2011 [6] [7].

Population growth could worsen the current unacceptably high maternal and child mortality. It could also put further pressure on environment, and social services. Moreover, population growth increases global burden of disease, poverty, and conflict [1] [2]. Such situations can be even worse in countries such as Ethiopia where inequality is a serious concern. Ethiopia is a mosaic of nationalities and peoples, having more than 80 different spoken languages [8]-[10]. Addressing the issue of inequality has been a serious problem in Ethiopia. To address this serious concern, the country has established a decentralized federal structure with nine regional states and two city administrations supported with constitution [9]-[11]. The Government of the Federal Democratic Republic of Ethiopia strongly believes that inequality in any sector could be better addressed through a federal system [11].

Considering population growth as a serious challenge, the Federal Democratic Republic of Ethiopia has developed several modern policies, and strategies to culminate extreme poverty, to revive degraded environment, to reduce maternal and child mortality and finally to develop Ethiopia from the current lowest to middle income countries in the coming couples of decades [12].

In this regard, several achievements have been registered in the country in various sectors including the health sector. Making Family Planning accessible to all families across the nation has been one of the successful interventions in Ethiopia [13]. Family planning services began in the 1966 in Ethiopia with the establishment of the Family Guidance Association of Ethiopia (FGAE). Not until the 1980s, did the Federal Ministry of Health (FMOH) add family planning to its maternal and child health program. In the first national survey in 1990, the CPR was only $2.3 \%$ [6] [7].

Data on trends of family planning utilization in Ethiopia reveals that there is reduction in unmet need over the last 21 years as documented in 2000, 2005, and 2011 EDHS [13] [14]. However, level of family planning utilization and unmet need still varies from region to region in this Federal State [5]. Furthermore, most studies on level of family planning utilization and unmet need focus on regions with large population size such as Amhara [15], and Oromo [16] [17] while data on level of family planning utilization, and unmet need in emerging regions such as Benshangul Gumuz is scarce.

Therefore, the genuine struggle of the government to address inequality through decentralized government structure needs to be supported with current data. The finding of this study will help reflecting successes, and help depicting the remaining challenges of family planning services utilization in hard to reach ethnic minorities, for instance, Gumuz communities in Ethiopia.

\section{Methods and Materials}

Community based cross-sectional study was conducted in Danguar District of Benshangul Gumuz National Regional State in June, 2013. The Benishangul Gumuz National Regional state (BGRS) is one of the nine Federal Constituents of Ethiopia located in the Northwest parts of Ethiopia [11]. Benishangul-Gumuz Regional State consists of five ethnic groups: Gumuz, Berta, Shinasha, Mao and Komo. However, there are also other ethnic groups living in the region in which their composition is specified as follows: Amhara, Oromo, Shinasha etc. [18]. According to the 2007 Ethiopian National population and housing census report, the total population of the Region was estimated to be 670,847 [19].

The Region is divided into three Zones: Danguar District is one of the seven districts of Metekel Zone. This district is bounded by Pawe, Guba, Wombera \& Bulen Districts of the region and Amhara National Regional State in the East, West, South and North, respectively. Admistratively, Dangur district is divided into 27 Kebeles (the smallest level of government administration). This district was selected because the majority of the target population-Gumuz communities—are living (Figure 1).

Based on the 2007 National population and housing census of Ethiopia, the population of the district is ap- 
proximately 40,781. Of these, 20,232 were females. There are two health centers, 27 health posts in the district $(25,26)$. The target population constitutes all married Gumuz women in child bearing age.

Gumuz communities were selected for this study because of the following reasons: they are living in less urbanized, in scattered manner with low infrastructure. Hence, they have maintained their cultural heritages. Moreover, Gumuz people are the second native majority in the region.

The sample size was calculated using single population proportion formula. Since data was not available for the study area, a 50\% proportion of family planning utilization was taken to get maximum sample size.

$$
\mathrm{n}=\frac{(\mathrm{Z} \alpha / 2)^{2} \mathrm{p}(1-\mathrm{p})}{\mathrm{W}^{2}}
$$

Where: $\mathrm{n}=$ the maximum sample size,

$\mathrm{Z}=$ standard normal distribution curve value for $95 \% \mathrm{CI}$ which is 1.96 ,

$\mathrm{P}=$ Proportion (50\%),

$\mathrm{W}=$ tolerable margin of sampling error $=0.05$ and $\alpha=$ the level of significance $=0.05$,

Non response rate $=10 \%$.

Hence, $\mathrm{n}=\frac{(\mathrm{Z} \alpha / 2)^{2} \mathrm{p}(1-\mathrm{p})}{\mathrm{W}^{2}}=(1.96)^{2} \times(0.5 \times 0.5)=384(0.05)^{2}$

The above sample size is for an infinite population ( $\mathrm{n}>10,000)$. The estimated number of Gumuz married woman in the district was 4620 . Therefore, the revised calculated sample size became

$$
384 / 1+(384 / 4620)=355
$$
585.

These multiplied with and 1.5 design effect plus $10 \%$ non response rate, the final calculated sample size was

The sample size was distributed to the sampled Kebeles proportionate to the size of the households in the respective selected 10 kebeles out of the 17 kebeles in the district. For households with more than one woman aged 15 - 49 years, only one was selected using lottery method. When the selected house hold was closed during

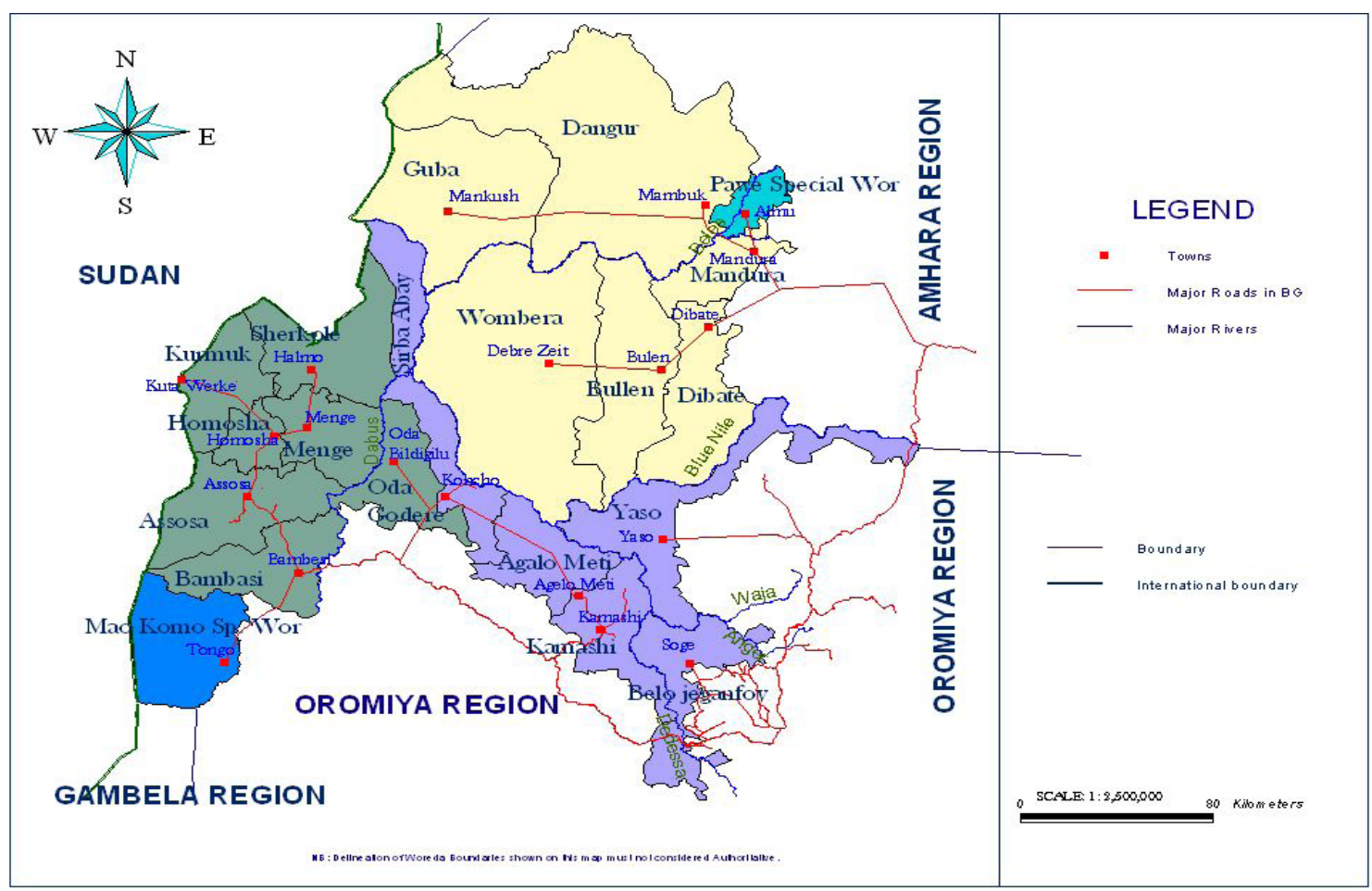

Figure 1. Administrative map of Benshangul Gumuz Regional State. 
data collection, three attempts were made before the household was excluded from the survey. When a selected household did not have a woman in reproductive age group, the next nearest household was considered.

Data were collected using commonly utilized structured questionnaires in Ethiopia including questionnaires used by Ethiopian demographic surveys. The questionnaire was originally prepared in English and its final version were translated into Amharic, and then back translated to English. Then, pre-test was conducted outside the study area. One day training was given for data collectors and supervisors. The training was focused on ethical aspect of research including privacy, confidentiality, and cultural sensitiveness and as to how to overcome cultural barriers during data collection. The data collection process was regularly checked by the supervisor and one of the investigators. To reduce non-response or reporting biases, interviews were conducted in places where other people could not overhear.

Practically data collection in this area was very difficult. To cop up with this challenge, the following techniques were implemented:

1) Data collection took place early in the morning before mothers left home.

2) The data collectors were selected from the local community members who were able to speak Amharic, well known and respected by the target communities. So that mothers could give the needed information to researcher. These helped us overcome the presumed challenges of data collection in the study area.

Data was analyzed using SPSS version 20 for windows. Logistic regression was fitted to assess possible association among variables, and strength of association was measured using odds ratio at $95 \%$ confidence interval.

Ethical Consideration: The study obtained Ethical clearance from GAMBY College of Medical Sciences. Written permission was also secured from the BGR Health Bureau. All the study participants were informed about the purpose of study, and their right to refuse. Privacy and confidentiality were maintained. Informed verbal consent was obtained from each study participant prior to the interview.

\section{Results}

A total of 530 women participated in the study. The response rate was $90 \%$. About $60 \%$ of study participants were Muslim by religion, and nearly $90 \%$ were not able to read and write, and were farmer by occupation. The age of the study participants ranges from 15 to 49 with mean age of $29.4 \pm 7.4$ years (Table 1 ).

Table 1. Socio-demographic characteristics of study participants, Dangur Woreda, 2013.

\begin{tabular}{ccc}
\hline Variable & Frequency $\mathbf{~}=\mathbf{5 3 0}$ & Percent (\%) \\
\hline Age & 38 & 7.2 \\
$15-19$ & 105 & 19.8 \\
$20-24$ & 140 & 26.4 \\
$25-29$ & 105 & 19.8 \\
$30-34$ & 88 & 16.6 \\
$35-40$ & 34 & 6.4 \\
$40-44$ & 20 & 3.8 \\
$45-49$ & & 87.0 \\
Mean $=29.4 \pm$ 7.4 & & 7.7 \\
Educational status & 461 & 5.3 \\
Not able to read and write & 41 & 60.0 \\
Able to read and write & 28 & 19.2 \\
Primary school & & 5.1 \\
Religion & 318 & 15.7 \\
Muslim & 102 & 89.6 \\
Orthodox & 27 & 1.2 \\
Protestant & 83 & 9.2 \\
Local religion & & \\
Occupation & 49 & \\
Housewife & 475 & \\
Farmer & 6 & \\
Government employ & & \\
\hline
\end{tabular}


More than 50\% considered themselves as poor. Majority of study participants 420 (79.2\%) did not have radio. About 366 (69.1\%) of participants had average monthly income of less than 500 birr (Table 2).

Almost all study participants (99.6\%) had history of pregnancy. Of them, nearly half $(49.1 \%)$ had five or more pregnancies. Age at first marriage varies from 7 - 23 years. Mean age at first marriage was 14. Eighty four percent of respondents married before the age of 18 years and $48.6 \%$ became pregnant before the age of 18 years. Mean number of living children was 3.7 (Table 3).

Table 2. Socio-economic characteristics of respondents, Dangur District, 2013.

\begin{tabular}{ccc}
\hline Variable & Frequency $\mathbf{N}=\mathbf{5 3 0}$ & Percent (\%) \\
\hline Possession of radio & & 79.2 \\
No & 420 & 20.8 \\
Yes & 110 & 69.1 \\
Monthly income (in Birr) & & 23.8 \\
$\leq 500$ & 366 & 3.4 \\
501 - 2000 & 126 & 3.8 \\
$>2000$ & 18 & 8.5 \\
no answer & 20 & 53.4 \\
Perceived economy & & 32.3 \\
Very poor & 45 & 5.9 \\
Poor & 283 & \\
Average & 171 & 31 \\
Well to do & 31 & \\
\hline
\end{tabular}

Table 3. Reproductive characteristics of study participants, Dangur District, 2013.

\begin{tabular}{|c|c|c|}
\hline Variable & Frequency N = 530 & Percent (\%) \\
\hline \multicolumn{3}{|l|}{ No of pregnancies } \\
\hline Never & 2 & 0.4 \\
\hline $1-2$ & 125 & 23.6 \\
\hline $3-4$ & 143 & 27.0 \\
\hline$\geq 5$ & 260 & 49.1 \\
\hline \multicolumn{3}{|l|}{ Mean $=4.6 \pm 2.36$} \\
\hline \multicolumn{3}{|l|}{ No of alive children } \\
\hline$\leq 2$ & 151 & 28.7 \\
\hline $3-5$ & 251 & 47.6 \\
\hline$\geq 6$ & 125 & 23.7 \\
\hline \multicolumn{3}{|l|}{$\begin{array}{c}\text { Mean }=3.7 \pm 1.94 \\
\text { Age at first pregnancy }\end{array}$} \\
\hline$\leq 15$ & 61 & 11.5 \\
\hline $16-26$ & 466 & 88.2 \\
\hline$>26$ Mean $=18 \pm 3.28$ & 1 & 0.1 \\
\hline \multicolumn{3}{|l|}{ Age at first marriage } \\
\hline$<15$ & 304 & 57.4 \\
\hline $15-20$ & 226 & 42.6 \\
\hline$>20$ Mean $=14 \pm 2.5$ & & \\
\hline
\end{tabular}


More than $80 \%$ of study participants had heard about modern family planning. Of these, nearly $80 \%$ of study participants knew injectables and 58.7 percent knew pills. The most frequently mentioned source of information for family planning were health professionals (79.7\%), friends (39.8\%), and radio (4.7\%). The most commonly mentioned methods were injectables and pills (Table 4).

Table 5 shows common misconceptions about family planning. As displayed in the table, nearly $60 \%$ of them think that using contraceptives will cause a loss of confidence between couples, about $35 \%$ think that contraceptives cause infertility, and more than $80 \%$ of them think that many children means high income.

About $20 \%$ of study participants were current users of modern contraceptive, and most of them claimed to use contraceptives in injection form (83\%). About $8 \%$ of study participants claimed to have experience of taking modern contraceptive methods, and discontinued because of several reasons (Table 6).

More than $80 \%$, and nearly $75 \%$ of study participants attribute culture, and desire for having more children not to use modern family planning methods. Besides, more than $40 \%$ of them attribute fear of side effect as a reason not to use family planning methods (Figure 2).

Table 4. Knowledge of study participants about types of family planning methods, Dangur Ditrict, 2013.

\begin{tabular}{ccc}
\hline Variable & Number & Percent \% \\
\hline Heard about MC & & 82.1 \\
Yes & 435 & 17.9 \\
No & 95 & 58.7 \\
Known contraceptive method & & 78.5 \\
Pills & 311 & 42.5 \\
Inject able & 416 & 14 \\
Norplant & 225 & 2.5 \\
Condom & 74 & \\
IUCD & 13 & \\
\hline
\end{tabular}

Table 5. Misconceptions about contraceptives among Gumuz married women, Dangur District, 2013.

\begin{tabular}{|c|c|c|}
\hline Assessment items & Number & Percent \\
\hline \multicolumn{3}{|c|}{ FP helps mother regain her strength } \\
\hline Agree & 118 & 22.3 \\
\hline disagree & 412 & 77.7 \\
\hline \multicolumn{3}{|c|}{ Child spacing helps improve the health of mothers and children } \\
\hline Agree & 250 & 47.2 \\
\hline Disagree & 280 & 52.8 \\
\hline \multicolumn{3}{|c|}{ FP practice will cause a loss of confidence between couples } \\
\hline Disagree & 221 & 41.7 \\
\hline Agree & 309 & 57.6 \\
\hline \multicolumn{3}{|c|}{ Contraceptive use causes infertility in a women } \\
\hline Disagree & 345 & 65.1 \\
\hline Agree & 185 & 34.9 \\
\hline \multicolumn{3}{|c|}{ Many children improve family income } \\
\hline Disagree & 103 & 19.4 \\
\hline Agree & 427 & 80.6 \\
\hline
\end{tabular}


Table 6. Utilization of modern contraceptive methods among Gumuz married women, Dangur District, 2013.

\begin{tabular}{|c|c|c|}
\hline Variable & Number & Percent \\
\hline \multicolumn{3}{|c|}{ Current use of contraceptive } \\
\hline Yes & 100 & 18.7 \\
\hline No & 430 & 80.2 \\
\hline \multicolumn{3}{|c|}{ Contraceptive currently in use } \\
\hline Pills & 9 & 9 \\
\hline Injection & 83 & 83 \\
\hline Norplant & 8 & 8 \\
\hline \multicolumn{3}{|l|}{ Discontinued } \\
\hline Yes & 42 & 7.9 \\
\hline No & 488 & 92.1 \\
\hline \multicolumn{3}{|l|}{ Ever used } \\
\hline Yes & 142 & 26.7 \\
\hline No & 388 & 73.3 \\
\hline \multicolumn{3}{|c|}{ Source of contraceptive } \\
\hline Health center & 22 & 15.4 \\
\hline Private clinic & 12 & 8.6 \\
\hline Health post & 108 & 76 \\
\hline
\end{tabular}

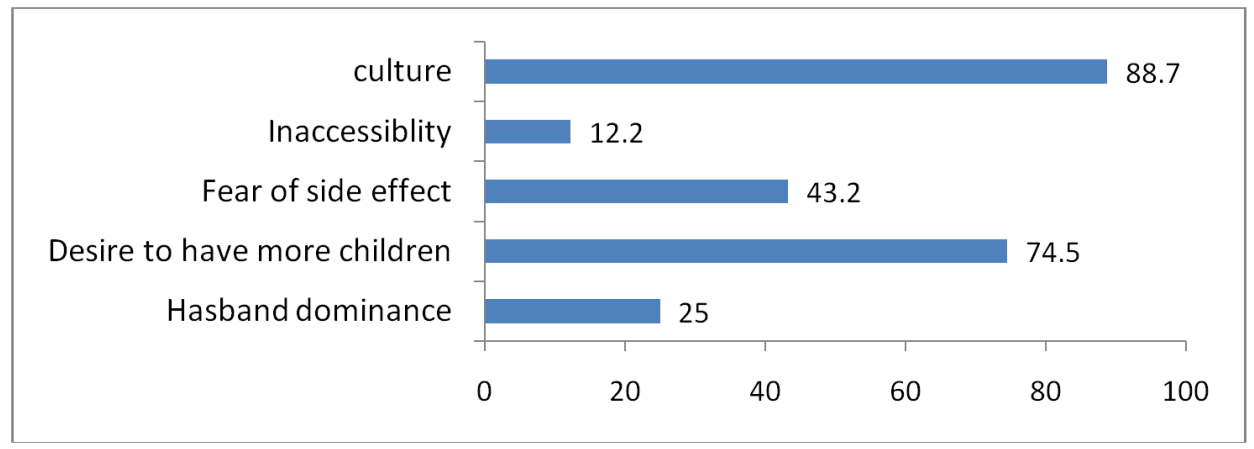

Figure 2. Reasons for not using modern family planning methods among married Gumuz women, Dangur District, 2013.

Educational status of women, number of children, knowledge about and attitude towards family planning were found to have statistically significant association with utilization of family planning methods. For instance, those women with primary level of education were 3 times more likely to use modern family planning method than those who were not able to read and write $[\mathrm{AOR}=3.60 ; 95 \% \mathrm{CI}=(1.49-8.70)]$ (Table 7).

\section{Discussions}

The major aim of this study was to assess level of modern family planning utilization and to identify factors associated to it. Being the second most populous nation of Africa, Ethiopia is a prototype example of nations which has been facing multitudes of challenges following rapid population growth including environmental degradation, chronic food insecurity, high maternal, and child mortality [5] [12] [13].

Cognizant of these multi-dimensional challenges of population growth, Ethiopia has developed several policies, 
Table 7. Factors associated with utilization of Modern Family Planning Methods among Gumuz Married women, Dangur District, 2013.

\begin{tabular}{|c|c|c|c|c|}
\hline \multirow[t]{2}{*}{ Characteristics } & \multicolumn{2}{|c|}{ Utilization of modern family planning } & \multicolumn{2}{|c|}{ OR (95\% CI) } \\
\hline & yes & no & COR & AOR \\
\hline \multicolumn{5}{|l|}{ Education of woman } \\
\hline Not able to read and write & 81 & 380 & 1.00 & 1.00 \\
\hline Able to read and write & 9 & 32 & $1.32(0.61-2.87)$ & $1.08(0.45-2.59)$ \\
\hline Primary school & 11 & 17 & $3.04(1.37-6.73)^{*}$ & $3.60(1.49-8.70)^{*}$ \\
\hline \multicolumn{5}{|l|}{ Religion } \\
\hline Muslim & 63 & 255 & 1.00 & 1.00 \\
\hline Orthodox & 19 & 83 & $0.93(0.52-1.64)$ & $0.87(0.47-1.60)$ \\
\hline Catholic & 8 & 19 & $1.70(0.65-4.35)$ & $1.81(0.61-5.41)$ \\
\hline Local religion & 11 & 72 & $0.62(0.31-1.24)$ & $0.59(0.28-1.22)$ \\
\hline \multicolumn{5}{|l|}{ Alive children } \\
\hline$\leq 2$ & 28 & 123 & 1.00 & 1.00 \\
\hline $3-5$ & 36 & 215 & $0.74(0.43-1.26)$ & $1.19(0.55-2.58)$ \\
\hline$\geq 6$ & 36 & 89 & $1.78(1.01-3.12)^{*}$ & $3.31(1.41-7.20)^{*}$ \\
\hline Attitude favorable & 46 & 153 & $1.54(1.02-2.39)^{*}$ & $1.58(1.03-2.50)^{*}$ \\
\hline unfavorable & 54 & 277 & 1.00 & 1.00 \\
\hline \multicolumn{5}{|l|}{ Knowledge } \\
\hline knowledgeable & 52 & 146 & $2.16(1.39-3.36)^{*}$ & $2.18(1.35-3.52)^{*}$ \\
\hline less knowledgeable & 47 & 285 & 1.00 & 1.00 \\
\hline
\end{tabular}

and strategies to culminate extreme poverty, to revive degraded environment, to reduce maternal and child mortality and finally to develop Ethiopia from the current lowest to middle income countries in the coming couples of decades [12].

In this regard, several achievements have been registered in the country in various sectors including the health sector. Making Family Planning accessible to all families across the nation has been one of the successful interventions in Ethiopia [5] [13].

The finding of the present study revealed that current use of modern family planning by married Gumuz women was 18.7\%. It was much lower than 2013 annual report of Dangur woreda (60\%) [20]. Possible explanation for this could be that the data from the district could have some intentional inflation. A research done by Tigist, 2012 in Afar Region cited by [21] indicated that communities in ethnic minorities such as Afar do not like to utilize modern family planning methods for they like to increase their population.

A study done in Southern Tigray (2011) revealed that contraceptive prevalence was (50.9\%) [22]. This figure is nearly three times higher than the finding of the present study. Possible explanation for this discrepancy could be the following: difference in population characteristics, culture, and access to information to family planning. It is very likely that communities in Southern Tigray have been exposed for information to family planning and other health related issues than communities in Gummuz. Fortunately, the current government structure has addressed such discrepancies by establishing a Federal State based on ethnic distribution of populations in the countryethnicity as pillar for geographic regionalization [9]-[11].

The result of the present study revealed that knowledge on family planning has statistically significant association with current contraception use. More than $80 \%$ of study participants in the present study claimed to have heard about modern family planning, and similar proportion of them knew injectables. This finding is consistent with research findings in Ethiopia [23] and abroad [24]. 
It is surprising to notice that how knowledge about modern family planning is successfully transferred to communities in Ethiopia even in hard to reach ones. This achievement can be considered as a real success for the Government of the Federal Democratic Republic of Ethiopia because this much has been achieved in hard to reach communities within less than two decades even before Information Education and Communication (IEEC) and Behavioural Change Communication Materials have been prepared using local languages.

This indicates how Federal and Regional Governments are committed to address the reproductive health needs of families in Ethiopia. The level of commitment of the Ethiopian Government in relation to success of family planning utilization has been recognized by USAID Africa Burea [13] recently. This paper indicated that Ethiopia is one of the three African nations with remarkable success in Family planning.

It is very likely that this good level of knowledge about family planning would decrease misconception surrounding modern family planning utilization. Studies indicate that knowledge about family planning is a prerequisite to obtaining access to and using a suitable contraceptive method in a timely and effective manner [5].

Study participants did mentioned several reasons for not using modern family planning methods. In the present study, more than $80 \%$ of study participants believed that many children mean high income, and hence the reason not to use modern family planning was desire to have more children for more than nearly $75 \%$ of the study participants. This result is supported by different findings from Sub-Saharan Africa and Asia [25].

In the present study about $25 \%$, and $40 \%$ of study participants claimed that they did not use modern family planning because their husbands did not want, and because of fear of side effect, respectively. This finding is consistent with findings from Sub-Saharan Africa and Asia [25].

Moreover, the findings of this study showed that culture was found to be number one obstacle to the use of modern family planning methods. In this locality, marriage is by exchange. If a family has several daughters, the family has a chance to get several potential wives as an exchange [26]. In this locality women are the most important working force. Therefore, men would like to have several wives. The Gumuz communities are well known for polygamy [5] [26].

Cultural barrier of modern family planning utilization is different in different area. For instance, the research conducted in Ruanda revealed that family size is largely determined by the male partner. The preference for boys over girls was described as overruling concern for family size. According to Delphine (2007) [27], Rwandan women prefer to give birth to boys in order to please their husbands and in-laws.

In Muslim dominated countries such as Pakistan [28], Egypt [29] and Malaysia [30] the justification not to use family planning is religious. In the present study, region was not a statistically significant factor. This difference might be partly explained by the fact that in Gumuz communities culture rather than religion that determines whether people use family planning or not.

In the present study, those women who had at least primary education had good attitude to modern contraceptive use than those women who could not read and write. Studies elsewhere revealed a similar pattern of relationship between educational status and maternal health service including family planning utilization [30] [31].

The present study revealed that misconceptions related to modern family planning are rampant in this particular community. Culture associated desire for getting large number of children, and the perception that utilization of modern contraceptive reduces confidence or rather trust among partners are the two most important ones that require discussion at this point.

The reflected desire to have large number of children in Gummuz communities is in line with the theory of demographic transition. This theory states that first child mortality should drastically decrease before parents do agree to decrease the number of children they want to have [32]. Child mortality is Gumuz communities is one of the highest in Ethiopia [5].

One of the most important misconceptions is in this study was that utilization of family planning including condom decreases confidence or trust. This is in line with findings in Behavioural surveillance survey studies in Ethiopia [33]. However, the good thing about the aforementioned misconceptions is that they are change amenable if targeted health education is given.

The major limitation of this study is that study participants were only women while men decide on most of the family affaires in this communities. However, this study brought the current status of modern family planning utilization in hard to reach ethnic minorities about whom literature are scarce.

\section{Conclusion}

This study witnessed how successful Ethiopia is in addressing reproductive health service inequalities in hard to 
reach communities. However, misconceptions surrounding family planning, and culture associated desire to have large family size should be addressed in a culture sensitive manner in Gummuz communities so that this success would further bear fruits. In this regard, Information Education Communication, and Behavioral Change Communication materials and messages should be prepared in local language to facilitate understanding to the wider community. Further research involving husbands is recommended.

\section{Acknowledgements}

Authors would like to appreciate Bahir Dar University and GAMBY College of Medical Sciences for opening an innovative joint MPH program which allows many MPH candidates to earn their $2^{\text {nd }}$ degree in public health including BM. We are also very much grateful for study participants, and data collectors.

\section{References}

[1] United Nations Economic and Social Affairs (2013) World Population Prospects. The 2012 Revision. Highlights and Advance Tables. New York.

[2] Cleland, J., Bernstein, S., Ezeh, A., Faundes, A., Glasier, A. and Innis, J. (2006) Family Planning: The Unfinished Agenda. The Lancet Sexual and Reproductive Health Series.

[3] Commission of the European Communities (2008) Demographic Challenges for European Region. Brussels.

[4] USAID (2010) The Cost of Family Planning in Ethiopia. USA.

[5] Ethiopia Demographic and Health Survey, Addis Ababa, Ethiopia, 2011.

[6] Ministry of Health of Ethiopia. Family planning in Ethiopia 2012.

[7] Ministry of Health of Ethiopia (2011) National Guidelines for Family Planning in Ethiopia, Addis Ababa, Ethiopia.

[8] Ministry of Health of Ethiopia (2010) Health Sector Development Programme IV 2010/11-2014/15.

[9] Habtu, A. (2003) Ethnic Federalism in Ethiopia: Background, Present Conditions and Future Prospects. Paper Submitted to the Second EAF International Symposium on Contemporary Development Issues in Ethiopia. The Ghion Hotel Addis Ababa Ethiopia.

[10] Balcha, B.G. (2007) Restructuring State and Society: Ethnic Federalism in Ethiopia. SPIRIT—Doctoral Programme Aalborg University Denmark SPIRIT Ph.D. Series. Thesis No. 8.

[11] Constitution of Ethiopia (1994) The Nation, Nationalities and Peoples of Ethiopia. Addis Abeba.

[12] Growth and Transformation Plan (2012) 2010/11-2014/15. Addis Abeba.

[13] USAID/Africa Bureau, USAID/Population and Reproductive Health, Ethiopia Federal Ministry of Health, Malawi Ministry of Health, Rwanda Ministry of Health (2012) Three Successful Sub-Saharan Africa Family Planning Programs: Lessons for Meeting the MDGs.

[14] Ayele, W., Tesfaye, H., Gebreyes, R. and Gebreselassie, T. (2013) Trends and Determinants of Unmet Need for Family Planning and Programme Options, Ethiopia. Further Analysis of the EDHS, 2000, 2005 and 2011.

[15] Portner, C., Beegle, K. and Christiaensen, L. (2013) Does Family Planning Reduce Fertility? Evidence from Rural Ethiopia.

[16] Ieda, A. (2012) Perceptions and Behaviour Related to Family Planning in a Rural Area in the Oromia Region, Ethiopia. Thesis, Department of Community Medicine Institute of Health and Society, the Faculty of Medicine University of Oslo, Oslo.

[17] Dibaba, Y. (2008) Factors Influencing Women’s Intention to Limit Child Bearing in Oromia, Ethiopia. The Ethiopian Journal of Health Development, 22, 28-33.

[18] Benshangul-Gumuz Regional State Website. http://www.benishangulgumuz.gov.et/

[19] Ethiopian National Population and Housing Census Report. Addis Ababa, 2007.

[20] Annual Report of Dangur District. Metekel Zone, Benishangul Gumuz Regional State , Ethiopia, 2013

[21] Ayele, W., Tesfaye, H., Gebreyes, R. and Gebreselassie, T. (2013) Trends and Determinants of Unmet Need for Family Planning and Programme Options, Ethiopia Further Analysis of the 2000, 2005, and 2011. Demographic and Health Surveys.

[22] Bayray, A. (2012) Assessment of Male Involvement in Family Planning among Men in the Southern Eastern Zone of Tigiray. Ethiopia Scholarly Journal of Medicine, 2, 1-10.

[23] Girma, E. (2011) Married Women’s Decision Making Power on Modern Contraceptive Use in Urban and Rural Southern Ethiopia. 
[24] Lwelamira, J., Mnyamagola, G. and Msaki, M.M. (2012) Knowledge, Attitude and Practice (KAP) towards Modern Contraceptives among Married Women of Reproductive Age in Mpwapwa District, Central Tanzania. Current Research Journal of Social Sciences, 4, 235-245.

[25] Creanga, A.A. (2011) Low Use of Contraception among Poor Women in Africa: An Equity Issue. Bulletin of the World Health Organization, 89, 258-266.

[26] Cultural, B.K. (2007) Practices that Affected the Status of Women in Benishangul Gumuz Mandura Woreda. Addis Abeba.

[27] Pinault, D. (2007) Cultural Barriers to Family Planning. Ruwanda.

[28] Pakistan Demographic and Health Survey, 2006-2007.

[29] Eltomy, E.M., Saboula, N.E. and Hussein, A.A. (2013) Barriers Affecting Utilization of Family Planning Services among Rural Egyptian Women. Eastern Mediterranean Health Journal, 19, 400-408.

[30] Najafi, F., Rahman, H.A. and Juni, M.H. (2011) Barriers to Modern Contraceptive Practices among Selected Married Women in a Public University in Malaysia. Global Journal of Health Science, 3.

[31] Lakew, Y., Reda, A.A., Tamene, H., Benedict, S. and Deribe, K. (2013) Geographical Variation and Factors Influencing Modern Contraceptive Use among Married Women in Ethiopia: Evidence from a National Population Based Survey. Reproductive Health, 10, 52.

[32] Kirk, D. (1996) Demographic Transition Theory. Population Studies, 50, 361-387. http://dx.doi.org/10.1080/0032472031000149536

[33] Ministry of Health of Ethiopia (2002) HIV/AIDS Behavioral Surveillance Survey (BSS) Round one, Ethiopia. 
Scientific Research Publishing (SCIRP) is one of the largest Open Access journal publishers. It is currently publishing more than 200 open access, online, peer-reviewed journals covering a wide range of academic disciplines. SCIRP serves the worldwide academic communities and contributes to the progress and application of science with its publication.

Other selected journals from SCIRP are listed as below. Submit your manuscript to us via either submit@scirp.org or Online Submission Portal.
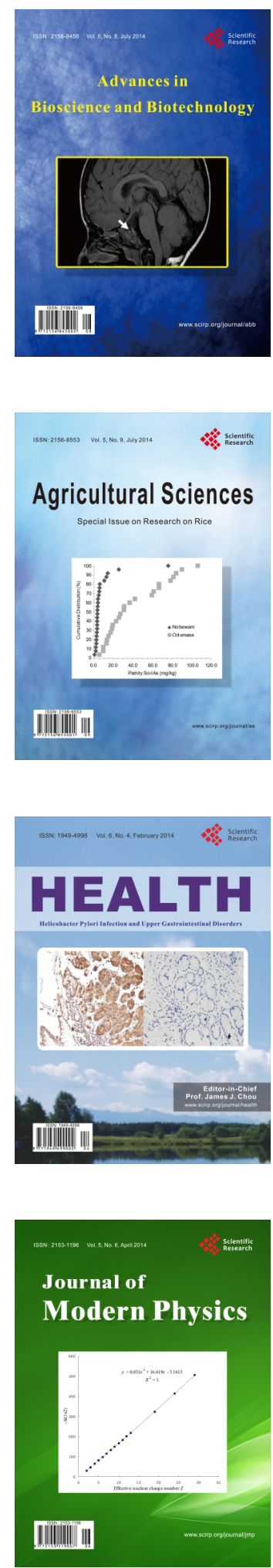
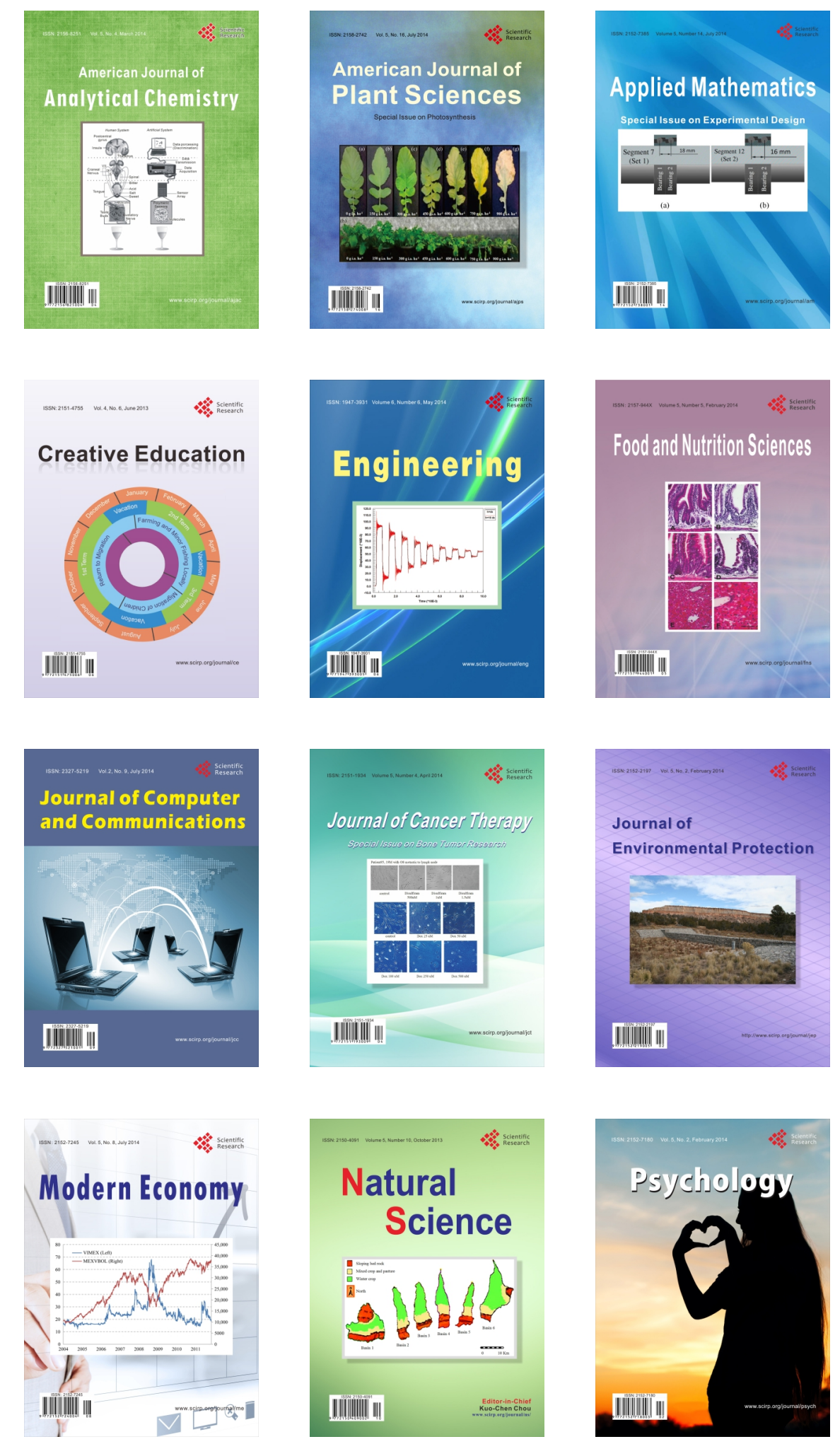